\title{
Resonance Raman intensity analysis of the excited state proton transfer dynamics of 2-nitrophenol in the charge-transfer band absorption
}

\author{
Ya-Qiong Wang, Hui-Gang Wang, Shu-Qiang Zhang, Ke-Mei Pei, and Xuming Zheng ${ }^{\text {a),b) }}$ \\ Department of Chemistry and State Key Laboratory of ATMMT (MOE), Zhejiang Sci-Tech University, \\ Hangzhou 310018, People's Republic of China \\ David Lee Phillips ${ }^{\mathrm{a}), \mathrm{c})}$ \\ Department of Chemistry, The University of Hong Kong, Pokfulam Road, Hong Kong SAR, \\ People's Republic of China
}

(Received 9 October 2006; accepted 9 November 2006; published online 7 December 2006)

\begin{abstract}
Resonance Raman spectra were obtained for 2-nitrophenol in cyclohexane solution with excitation wavelengths in resonance with the charge-transfer (CT) proton transfer band absorption. These spectra indicate that the Franck-Condon region photodissociation dynamics have multidimensional character with motion along more than 15 normal modes: the nominal $\mathrm{CCH}$ bend $+\mathrm{CC}$ stretch $\nu_{12}\left(1326 \mathrm{~cm}^{-1}\right)$, the nominal CCC bend $\nu_{23}\left(564 \mathrm{~cm}^{-1}\right)$, the nominal CO stretch +NO stretch + CC stretch $\nu_{14}\left(1250 \mathrm{~cm}^{-1}\right)$, the nominal CCH bend $+\mathrm{CC}$ stretch $+\mathrm{COH}$ bend $\nu_{15}\left(1190 \mathrm{~cm}^{-1}\right)$; the nominal $\mathrm{CCH}$ bend $+\mathrm{CC}$ stretch $\nu_{17}\left(1134 \mathrm{~cm}^{-1}\right)$, the nominal CCC bend $+\mathrm{CC}$ stretch $\nu_{22}\left(669 \mathrm{~cm}^{-1}\right)$, the nominal $\mathrm{CCN}$ bend $\nu_{27}\left(290 \mathrm{~cm}^{-1}\right)$, the nominal $\mathrm{NO}_{2}$ bend $+\mathrm{CC}$ stretch $\nu_{21}\left(820 \mathrm{~cm}^{-1}\right)$, the nominal CCO bend $+\mathrm{CNO}$ bend $\nu_{25}\left(428 \mathrm{~cm}^{-1}\right)$, the nominal CC stretch $\nu_{7}\left(1590 \mathrm{~cm}^{-1}\right)$, the nominal NO stretch $\nu_{8}\left(1538 \mathrm{~cm}^{-1}\right)$, the nominal CCC bend $+\mathrm{NO}_{2}$ bend $\nu_{20}\left(870 \mathrm{~cm}^{-1}\right)$, the nominal CC stretch $\nu_{6}\left(1617 \mathrm{~cm}^{-1}\right)$, the nominal $\mathrm{COH}$ bend $+\mathrm{CC}$ stretch $\nu_{11}\left(1382 \mathrm{~cm}^{-1}\right)$, nominal CCH bend $+\mathrm{CC}$ stretch $\nu_{9}\left(1472 \mathrm{~cm}^{-1}\right)$. A preliminary resonance Raman intensity analysis was done and the results for 2-nitrophenol were compared to previously reported results for nitrobenzene, $p$-nitroaniline, and 2-hydroxyacetophenone. The authors briefly discuss the differences and similarities in the CT-band absorption excitation of 2-nitrophenol relative to those of nitrobenzene, $p$-nitroaniline, and 2-hydroxyacetophenone. () 2006 American Institute of Physics. [DOI: $10.1063 / 1.2404668]$
\end{abstract}

\section{INTRODUCTION}

Nitroalkanes and nitroaromatic compounds are of interests as energetic and functional molecules that can have applications as explosive materials. ${ }^{1,2}$ Nitroalkanes and nitroaromatic compounds may also have a possible role in atmospheric chemistry and photochemistry. ${ }^{3,4}$ Thus, there have been extensive experimental and theoretical studies of the dissociation and photodissociation reactions of nitroalkanes and nitroaromatics. ${ }^{5-28}$ Nitroalkanes have absorption bands near $\sim 200 \mathrm{~nm}$ (called the $B$-band absorption with $\varepsilon$ $\left.=4000-6000 \mathrm{l} \mathrm{mol}^{-1} \mathrm{~m}^{-1}\right)$ and that have been assigned to an allowed $X\left({ }^{1} A_{1}\right) \rightarrow{ }^{1} B_{2}$ or $\pi \rightarrow \pi^{*}$ transition which is localized on the $\mathrm{NO}_{2}$ group based on several experimental and theoretical studies. ${ }^{5-10}$ Excitation of the nitroalkanes within the $B$-band absorption gives rise to mainly cleavage of the $\mathrm{C}-\mathrm{N}$ bond with an almost unity quantum yield to produce $\mathrm{NO}_{2}$ (major channel) and NO (minor channel) fragments even though the $\mathrm{NO}_{2}$ group is initially excited. ${ }^{11-14}$ Broad and structureless $B$-band absorptions are observed for both gas and solution phase nitromethane and other nitroalkanes. This suggests that the total electronic dephasing is mostly due to photodissociation before the first vibrational recurrence takes

\footnotetext{
a) Authors to whom correspondence should be addressed.

${ }^{b}$ Fax: 86-0571-86843223. Electronic mail: zhengxuming126@126.com

${ }^{c)}$ Fax: 852-2857-1586. Electronic mail: phillips@hkucc.hku.hk
}

place. The observation of NO fragments following $B$-band excitation of nitromethane involves a secondary dissociation of the $\mathrm{NO}_{2}$ and/or the isomerization of nitromethane to methyl nitrite, $\mathrm{CH}_{3} \mathrm{ONO}$, prior to dissociation. ${ }^{14,15}$ Resonance Raman spectroscopy has been employed to study the shorttime photodissociation dynamics of nitroalkanes in the gas, liquid, and glass phases within the $B$-band absorption. ${ }^{13,16-19}$ The $B$-band resonance Raman spectra of nitromethane were similar to each other in the gas, liquid, and glass phases, and exhibited a large overtone progression in the nominal $\mathrm{NO}_{2}$ symmetric stretch mode and relatively weak combination band progressions of the $\mathrm{C}-\mathrm{N}$ stretch fundamental, the $\mathrm{ONO}$ symmetric bend fundamental, and two quanta of the $\mathrm{NO}_{2}$ antisymmetric stretch mode with the overtones of the $\mathrm{NO}_{2}$ symmetric stretch mode. ${ }^{13,16,17}$ Larger nitroalkanes have been examined in both the gas and liquid phases and their Franck-Condon region photodissociation dynamics were found to be similar to that of the nitromethane system. ${ }^{18,19}$

Nitrobenzene has a transition-allowed absorption band near $\sim 250 \mathrm{~nm}$ [called the charge transfer (CT)-band absorption] that has been assigned to a $1{ }^{1} A_{1} \rightarrow 2{ }^{1} A_{1}$ or $\pi$ (benzene ring) $\rightarrow \pi^{*}\left(\mathrm{NO}_{2}\right)$ transition based on both experimental and theoretical investigations. ${ }^{20,21}$ A gas phase photolysis study of nitrobenzene with excitation wavelengths between 220 and $280 \mathrm{~nm}$ observed three primary dissociation pathways. ${ }^{22}$ Two of the pathways were $\mathrm{C}_{6} \mathrm{H}_{5} \mathrm{NO}_{2} \rightarrow \mathrm{C}_{6} \mathrm{H}_{5}$ 
$+\mathrm{NO}_{2}$ and $\mathrm{C}_{6} \mathrm{H}_{5} \mathrm{NO}_{2} \rightarrow \mathrm{C}_{6} \mathrm{H}_{5} \mathrm{NO}+\mathrm{O}$ and the third pathway involved NO production. It was proposed that the nitrobenzene molecule first isomerized to phenyl nitrite $\mathrm{C}_{6} \mathrm{H}_{5} \mathrm{ONO}$ and subsequently decomposed by breaking the $\mathrm{C}-\mathrm{ONO}$ bond to release $\mathrm{NO}_{2}$, or the $\mathrm{O}-\mathrm{NO}$ bond to produce $\mathrm{NO}$, or the $\mathrm{ON}-\mathrm{O}$ bond to form $\mathrm{O}^{22} \mathrm{Ab}$ initio calculations were performed and provided further support for the rearrangement pathway as the most likely dissociation channel for the production of NO (Ref. 23) and the barrier height for the rearrangement of nitrobenzene to phenylnitrite was determined from the characterization of the transition state. ${ }^{24}$ Resonance Raman spectroscopy and density functional theory (DFT) computations were used to study the Franck-Condon region photodissociation dynamics of nitrobenzene in cyclohexane solution $^{25}$ and a resonance Raman intensity analysis indicated that most of the short-time photodissociation dynamics in the Franck-Condon region occurs mostly along the nominal $\mathrm{NO}_{2}$ stretch and nominal benzene ring symmetry stretch normal modes accompanied by other four smaller normal modes. The short-time dynamics for nitrobenzene were found to be noticeably different from those of nitroalkanes with substantially less vibrational reorganizational energy taking place in the Franck-Condon region of nitrobenzene compared to the nitroalkanes.

There have not been many investigations of the substitution effect on the Franck-Condon region photodissociation dynamics of nitrobenzene compounds. The $\mathrm{NO}_{2}$ and $\mathrm{NO}$ fragment channels have been observed for three nitrotoluene isomers. ${ }^{26-29}$ Significant $\mathrm{OH}$ production was observed in the dissociation of $o$-nitrotoluene and this was attributed to a so-called ortho effect that involves a bicyclic intermediate and subsequent rearrangement to the nitrite form prior to fragmentation. ${ }^{28}$ The product internal energy distributions in the NO fragment from dissociation of $o$-nitrotoluene between 224 and $238 \mathrm{~nm}$ were noted to be different from those of the NO fragments produced from dissociation of nitrobenzene or $\mathrm{NO}_{2}{ }^{29}$

In this paper, we report a preliminary resonance Raman intensity analysis study of the short-time excited state proton transfer dynamics of 2-nitrophenol in its CT-band absorption. 2-nitrophenol is one of the simplest $\mathrm{OH}$ derivatives of nitrobenzene and is known to possess strong hydrogen bonding interactions between the $\mathrm{OH}$ group and the $\mathrm{NO}_{2}$ group in its ground state. This allows us to examine how intramolecular hydrogen bonding interaction influences the Franck-Condon region photodissociation dynamics of nitroaromatic compounds in the CT-band absorption. We acquired 355 and $369 \mathrm{~nm}$ resonance Raman spectra and absolute Raman cross section measurements. We then simulated the experimental absorption and resonance Raman cross section with timedependent wave packet calculations using a simple model in order to characterize the short-time excited state dynamics. We also compare the results obtained for 2-nitrophenol here to analogous results previously obtained for nitrobenzene to examine the differences and/or similarities between the two nitroaromatic systems.

\section{EXPERIMENTAL AND COMPUTATIONAL METHODS}

\section{A. FTIR, FT-Raman, and resonance Raman experiments}

The Fourier transition infrared (FTIR) spectrum of 2-nitrophenol in the solid state was acquired with $2 \mathrm{~cm}^{-1}$ resolution by a Nicolet 370 FTIR spectrometer. The FTRaman spectrum of neat solid 2-nitrophenol was obtained with $2 \mathrm{~cm}^{-1}$ resolution and $532 \mathrm{~nm}$ excitation using a Thermo Nicolet FT-Raman 960 spectrometer. To avoid the aggregation of 2-nitrophenol, a concentration-dependent UVVIS experiment was carried out. The UV-VIS spectra showed no discernible changes over about $0.001 M-0.050 M$ but some changes appear above $0.050 \mathrm{M}$, possibly due to aggregation. The resonance Raman experiments used concentrations in the $0.007 M-0.015 M$ range for 2-nitrophenol in cyclohexane solvent so as to avoid possible appreciable aggregation. The power dependence of the resonance Raman spectra was tested and a lower power was used during the resonance Raman measurements to avoid any unwanted ground state depletion or mutiphoton processes. The use of high peak power can lead to the depletion of the ground state species and could cause the Raman band intensities of the sample relative to those of solvent to change when the laser power increases too much. Higher peak power can also produce more photochemical intermediates or cause multiphoton processes to occur during the laser pulse. These can also interfere with absolute Raman cross section measurements. ${ }^{30}$

The methods and experimental apparatus used for the resonance Raman experiments have been described elsewhere ${ }^{31-44}$ so only a short description will be given here. The harmonics of a nanosecond neodymium-doped yttrium aluminum garnet laser and their hydrogen Raman shifted laser lines produced the excitation wavelengths used in the resonance Raman experiments. The excitation laser beam was loosely focused to about a $0.5 \mathrm{~mm}$ diameter spot size onto a flowing liquid stream of sample and a backscattering geometry was used for sample excitation and for collection of the Raman scattered light by reflective optics. The Raman scattered light was imaged through a polarizer and entrance slit of a $0.5 \mathrm{~m}$ spectrograph whose grating dispersed the light onto a liquid nitrogen cooled charge-coupled device (CCD) mounted on the exit of the spectrograph. The CCD acquired the Raman signal for about 90-120 s before being read out to an interfaced personal computer and about 10-30 of these scans were summed to get the resonance Raman spectrum. The Raman shifts of the resonance Raman spectra were calibrated using the known vibrational frequencies of the cyclohexane solvent Raman bands and the solvent Raman bands were subtracted from the resonance Raman spectra using an appropriately scaled solvent spectrum. The spectra of an intensity calibrated deuterium lamp were used to correct the resonance Raman spectral intensities for the variation in detection efficiency as a function of wavelength and portions of the resonance Raman spectra were fitted to a base line plus a sum of Lorentzian bands to find the integrated areas of the Raman bands.

The absolute Raman cross sections of the 2-nitrophenol resonance Raman spectra were determined relative to the 
$802 \mathrm{~cm}^{-1}$ Raman band of the cyclohexane solvent and the depolarization ratio $\rho$ of all the Raman fundamental for 2-nitrophenol was estimated to be $1 / 3$ since the $A$-band absorption is mainly a single nondegenerate electronic state that is well separated from the $B$-band absorption (for details Sec. III B). An ultraviolet/visible (UV/VIS) spectrometer was used to determine the concentrations of the 2-nitrophenol sample before and after each measurement and the absorption spectra changed by $<5 \%$ due to photodecomposition and/or solvent evaporation and the absolute Raman cross sections were computed using the average concentration before and after three measurements and finding the mean of three trials to get a final value for the excitation wavelengths determined.

\section{B. Time-dependent wave packet calculations to model the resonance Raman intensities and absorption spectrum}

The absorption spectrum and resonance Raman intensities were modeled using Heller's time-dependent wave packet approach to resonance Raman scattering. ${ }^{45-48}$ The absorption spectrum was calculated using the following expression:

$$
\begin{aligned}
\sigma_{A}\left(E_{L}\right)= & \left(4 \pi e E_{L} M_{0}^{2} / 3 n \hbar c\right) \\
& \times \int_{-\infty}^{\infty} G(\delta) d \delta \operatorname{Re} \int_{0}^{\infty} d t\langle 0 \mid 0(t)\rangle \\
& \left.\times \exp \left[i\left(E_{L}+\varepsilon_{0}\right)\right] t / \hbar\right] \exp [-\Gamma t / \hbar],
\end{aligned}
$$

and the resonance Raman intensities are calculated using the following formula:

$$
\begin{aligned}
\sigma_{A}\left(E_{L}\right)= & \left(8 \pi e^{4} E_{S}^{3} E_{L} M_{0}^{4} / 9 \hbar^{6} c^{4}\right) \\
& \times \int_{-\infty}^{\infty} G(\delta) d \delta \mid \int_{0}^{\infty} d t\langle f \mid 0(t)\rangle \\
& \left.\times \exp \left[i\left(E_{L}+\varepsilon_{0}\right)\right] t / \hbar\right]\left.\exp [-\Gamma t / \hbar]\right|^{2},
\end{aligned}
$$

where $E_{L}$ is the incident photon energy, $M_{0}$ is the transition length evaluated at the equilibrium geometry, $f$ is the final state for the Raman scattering, and $n$ is the solvent index of refraction. The term $\exp [-\Gamma t / \hbar]$ is a homogeneous damping function that has contributions from the excited state population decay and pure dephasing. $G(\delta)$ is an inhomogeneous distribution of transition energies. $|0(t)\rangle=e^{-i H t / \hbar}|0\rangle$ which is $|0\rangle$ propagated on the excited state surface for a time $t$ and $H$ is the excited state vibrational Hamiltonian.

The ground and excited state potential energy surfaces were simulated using harmonic oscillators with their minima set apart by an amount $\Delta$ (with dimensionless units for the ground state normal coordinates). The simple model used here did not employ Duschinsky rotation ${ }^{47,48}$ of the normal modes and the ground and excited state harmonic oscillators had the same vibrational frequency. The resonance Raman intensities of the first several overtones as well as the combination bands and the absorption spectrum are determined mainly by the slope of the excited state surface in the
Franck-Condon region in the absence of any vibrational recurrences and the featureless solution phase A-band absorption spectra of 2-nitrophenol suggest that the total electronic dephasing and/or population decay occurs before the first vibrational recurrence of any Franck-Condon active modes. For the resonance Raman bands observed in our experimental spectra, the $\langle f \mid I(t)\rangle$ overlaps decay and have a negligible value after about $30 \mathrm{fs}$ and the effects of solvent dephasing used a simple exponential decay term $(\exp [-t / \tau])$. The bound harmonic oscillator model used here only provides a convenient method to simulate the Franck-Condon region portion of the excited state surface that determines the resonance Raman intensities and absorption spectrum and does not in any way imply that the excited state is actually bound.

\section{Density functional theory calculations}

DFT calculations ${ }^{49,50}$ were done to find the optimized geometry and vibrational frequencies as well as the electronic transition energies for the ground or excited electronic states of 2-nitrophenol. Complete geometry optimization and vibrational frequency computations were computed by using the B $3 \mathrm{LYP} / 6-31+\mathrm{G}(d f, p d)$ level of theory with a $C_{s}$ symmetry, while the electronic transition energies were calculated using the B3LYP-TD/6-31+G $(d f, p d)$ level of theory. All of the density functional theory calculations made use of the GAUSSIAN program software suite. ${ }^{51}$

\section{RESULTS AND DISCUSSION}

\section{A. Ground state proton transfer tautomerization}

2-nitrophenol has several intramolecular hydrogen transfer tautomers that are found to exist after thermal decomposition $^{52}$ and $a b$ initio and DFT calculations were done to study their molecular structures and photo-thermalinduced reactions. It is possible that there exist two primary intramolecular proton transfer tautomers called the facial tautomer and the backward tautomer. ${ }^{53-55}$ Density functional theory calculations were done to determine the minimum energy structure of 2-nitrophenol and its possible proton transfer tautomers and only the backward tautomer was found to have a direct primary proton transfer. The facial tautomer does not exist on both the B3LYP/6-311G ${ }^{* * *}$ and the $\mathrm{CCD}(\mathrm{S}) \mathrm{T} / \mathrm{cc}-\mathrm{PVTZ}$ potential energy surfaces. These results are different from those found for 2-hydroxyacetophenone (OHAP) which only has the facial tautomer but does not have the backward tautomer. ${ }^{56}$ The transition structure for 2-nitrophenol and the backward tautomer was also determined and Fig. 1 displays the geometry structures found for 2-nitrophenol, the facial tautomer, the backward tautomer, and one possible transition state between 2-nitrophenol and the backward tautomer. The computed parameters are indicated next to their selected bond lengths and bond angles in Fig. 1. The backward tautomer is energetically $28.1 \mathrm{kcal} / \mathrm{mol}$ higher than 2-nitrophenol. The structural parameters between 2-nitrophenol and its backward tautomer are noticeably different. While the $\mathrm{C}_{1}-\mathrm{C}_{2}, \mathrm{C}_{2}-\mathrm{N}_{8}$, and $\mathrm{N}_{8}-\mathrm{O}_{9}$ bonds of the backward tautomer are longer than those of 2-nitrophenol by more than $0.08 \AA$, the $\mathrm{C}_{1}-\mathrm{O}_{7}$ bond of the backward tautomer is $0.1 \AA$ shorter than that of 
<smiles>O=[N+]([O-])C1CCCCC1O</smiles>

(A) 2-Nitrophenol

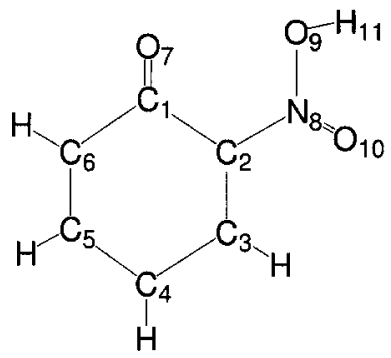

(C) Backward tautomer<smiles>O=C1CCCCC1[N+](=O)O</smiles>

(B) Facial tautomer<smiles>O=C1CCCCC1[N+](=O)[O-]</smiles>

(D) Transition structure for $\mathrm{A}$ and $\mathrm{C}$
FIG. 1. B3LYP/6-31+G $(d f, p d)$ computetd geometry parameters for the ground state of 2-nitrophenol (A), possible facial proton transfer tautomer in the ground state (B), backward proton transfer tautomer (C), and the transition state structure for 2-nitrophenol and the backward tautomer (D).

2-nitrophenol. These four bonds undergo the largest geometry changes during the processes of ground state proton transfer tautomerization. The other $\mathrm{C}-\mathrm{C}$ bond length changes for 2-nitrophenol are moderate and within 0.06-0.024 longer or shorter than those of the backward tautomer. All of the bond angle changes are within $3^{\circ}$ except for the changes of $\mathrm{C}_{2}-\mathrm{N}_{8}-\mathrm{O}_{10}$ and $\mathrm{O}_{9}-\mathrm{N}_{8}-\mathrm{O}_{10}$ bond angles that change by $7.3^{\circ}$ and $6.7^{\circ}$, respectively. The transition state between 2-nitrophenol and its backward tautomer has a molecular structure with the nitro and hydroxyl groups distorted away from benzene ring plane. The transition barrier height is $33.8 \mathrm{kcal} / \mathrm{mol}$ above 2-nitrophenol.

\section{B. Absorption spectra}

Figure 2 shows the absorption spectra of 2-nitrophenol, nitrobenzene, and phenol in cyclohexane solution. The excitation wavelengths for the resonance Raman experiments done for 2-nitrophenol are indicated above the absorption spectrum of panel A in Fig. 2. Table I lists the B3LYP$\mathrm{TD} / 631+\mathrm{G}(d f, p d)$ computed electronic transition energies and their oscillator strengths for 2-nitrophenol. Table I shows that among the calculated electronic transitions above $200 \mathrm{~nm}$ there are five electronically allowed transition bands which are located at $361,275,222,210$, and $203 \mathrm{~nm}$ that have oscillator strengths of $f=0.0602,0.1991,0.0173$, 0.0463 , and 0.1687 , respectively. The first three largest calculated bands at $361 \mathrm{~nm}(f=0.0602), 275 \mathrm{~nm}(f=0.1991)$, and $203 \mathrm{~nm}(f=0.1687)$ are in good agreement with the three intense experimental absorption bands at $347 \mathrm{~nm}(f$ $=0.0689), 271.6 \mathrm{~nm}(f=0.1293)$, and $211.6 \mathrm{~nm}(f=0.2225)$, respectively, for 2-nitrophenol. The $A$-band absorption of 2-nitrophenol is located at $347 \mathrm{~nm}$ and is clearly separated from the $B$ band at $271.6 \mathrm{~nm}$. The $A$-band absorption is

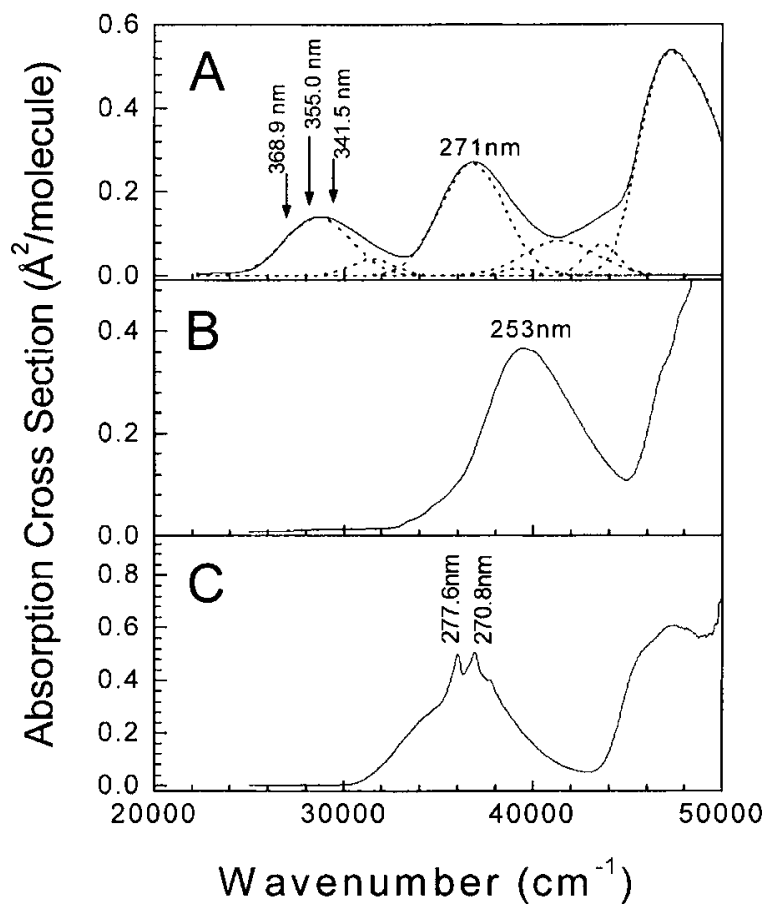

FIG. 2. Absorption spectra of 2-nitrophenol (A), nitrobenzene (B), and phenol (C) in cyclohexane solution (solid line). The excitation wavelengths used for the resonance Raman experiments are indicated above the absorption spectrum in $\mathrm{nm}$.

mostly a single, nondegenerate electronic state. The $B$-band absorption of 2-nitrophenol is observed at $271.6 \mathrm{~nm}$ and is assigned to a charge-transfer excitation from the benzene ring to the nitro group and is similar in nature to the assignment made to the $253 \mathrm{~nm} A$-band absorption of nitrobenzene. $^{21,25}$ The $347 \mathrm{~nm} \quad A$-band absorption of 2-nitrophenol is a new band absorption that is assigned to $\pi$ (benzene ring) $\rightarrow \pi^{*}$ (nitro group) transition and is different from the $A$-band absorption $(\sim 275 \mathrm{~nm})$ of phenol that is assigned to a $\pi \rightarrow \pi^{*}$ transition of phenyl on the basis of our time dependent (TD)-DFT computation natural orbital analysis results and electron loss spectroscopic results. ${ }^{57}$ Our natural orbital analysis shows the $\pi$ orbital of the benzene ring corresponding to the $347 \mathrm{~nm}$ band of 2-nitrophenol is more delocalized into the $\mathrm{OH}$ and the $\mathrm{NO}_{2}$ groups, while the $\pi^{*}$ orbital of the nitro group is more delocalized into the benzene ring and the $\mathrm{OH}$ group with respect to nitrobenzene. This indicates that there is a strong ground state intramolecular hydrogen bonding interaction. It appears that our 368.9, 355 , and $341.5 \mathrm{~nm}$ excitation wavelengths used in the resonance Raman experiments should be mostly on resonance with the $A$-band absorption of 2-nitrophenol. The depolarization ratio $\rho=1 / 3$ was used for the absolute Raman cross section measurements of all bands observed in our 368.9, 355 , and $341.5 \mathrm{~nm}$ resonance Raman spectra. This is based on the selection rule that the depolarization ratio $\rho$ should be $1 / 3$ for all bands if the Raman intensity derives solely from a single, nondegenerate electronic state in liquids at room temperature. $^{48}$

\section{Vibrational analysis and resonance Raman spectra}

Table II presents the FT-Raman and FTIR experimentally measured vibrational frequencies and compares them to 
TABLE I. B3LYP-TD/6-31+G $(d f, p d)$ computed singlet transition energies of 2-nitrophenol.

\begin{tabular}{|c|c|c|c|c|c|c|}
\hline \multirow[b]{2}{*}{ States $\left(C_{s}\right)$} & \multirow[b]{2}{*}{ Orbitals } & \multirow[b]{2}{*}{ Characters } & \multicolumn{2}{|c|}{ Singlet transition energies } & \multicolumn{2}{|c|}{ Oscillator strength $f$} \\
\hline & & & Calc. (nm) & Expt. (nm) & Calc. & Expt. \\
\hline $2{ }^{1} A^{\prime}$ & $36 \rightarrow 37$ & ${ }^{1}\left(\pi, \pi^{*}\right)$ & 361 & 347 & 0.0602 & 0.0689 \\
\hline $1{ }^{1} A^{\prime \prime}$ & $34 \rightarrow 37$ & ${ }^{1}\left(\pi, \pi^{*}\right)$ & 320 & 316 & 0.0000 & 0.0131 \\
\hline $2{ }^{1} A^{\prime \prime}$ & $33 \rightarrow 37$ & ${ }^{1}\left(\sigma, \pi^{*}\right)$ & 286 & & 0.0005 & 0.0042 \\
\hline $3{ }^{1} A^{\prime}$ & $35 \rightarrow 37$ & ${ }^{1}\left(\pi, \pi^{*}\right)$ & 275 & 272 & 0.1991 & 0.1293 \\
\hline $4{ }^{1} A^{\prime}$ & $36 \rightarrow 38$ & ${ }^{1}\left(\pi, \pi^{*}\right)$ & 222 & 228 & 0.0173 & 0.0194 \\
\hline $5^{1} A^{\prime}$ & $32 \rightarrow 37$ & ${ }^{1}\left(\pi, \pi^{*}\right)$ & 210 & 216 & 0.0463 & 0.0457 \\
\hline $6{ }^{1} A^{\prime}$ & $32 \rightarrow 37$ & ${ }^{1}\left(\pi, \pi^{*}\right)$ & 203 & 212 & 0.1687 & 0.2225 \\
\hline $3^{1} A^{\prime \prime}$ & $30 \rightarrow 37$ & ${ }^{1}\left(\sigma, \pi^{*}\right)$ & 200 & & 0.0002 & 0.0844 \\
\hline
\end{tabular}

the $\mathrm{B} 3 \mathrm{LYP} / 6-31+\mathrm{G}(d f, p d)$ computed vibrational frequencies of 2-nitrophenol. The notations and assignments of the vibrations are based on the visualization MOLDEN/MIX software and are similar to those of Kovacs. ${ }^{58}$ The vibrations of the hydroxy and the nitro groups are strongly influenced by the intramolecular hydrogen bonding interaction. The $\mathrm{NO}_{2}$ torsional frequency (located at $85 \mathrm{~cm}^{-1}$ ) of $o$-nitrophenol is increased by $35 \mathrm{~cm}^{-1}$ with respect to that $\left(50 \mathrm{~cm}^{-1}\right)$ of nitrobenzene. The $\mathrm{OH}$ stretching frequency $\left(3253 \mathrm{~cm}^{-1}\right)$ decreases by $400 \mathrm{~cm}^{-1}$ while the $\mathrm{OH}$ torsional frequency $\left(690 \mathrm{~cm}^{-1}\right)$ increases by $380 \mathrm{~cm}^{-1}$ for $o$-nitrophenol with respect to the corresponding bands (3656 and $309 \mathrm{~cm}^{-1}$ ) of phenol. The vibrational motions of $\mathrm{OH}, \mathrm{NO}_{2}$, and the phenyl ring group are strongly mixed with each other and distributed among different modes.

Figure 3 shows an overview of the $A$-band resonance Raman spectra of 2-nitrophenol obtained with 369.9 and $355 \mathrm{~nm}$ excitation wavelengths and Fig. 4 presents an expanded view of the resonance Raman spectrum obtained with $355 \mathrm{~nm}$ excitation with tentative vibrational assignments indicated above the spectrum. The spectra shown in Fig. 3 and 4 have been corrected for sample reabsorption as well as the wavelength dependence response of the detection system and the solvent Raman bands were removed from the spectra by subtracting an appropriately scaled solvent spectrum and regions of the solvent subtraction artifacts are indicated by asterisks. We note that the intensity of some Raman bands in the spectrum may have contributions from several Raman bands that have very close Raman shifts due to the limited resolution of the solution phase spectra and therefore, the Raman band labels in Fig. 4 only indicate the largest Raman band contributions to each Raman feature. Most of the resonance Raman features can be assigned to the fundamentals, overtones, and combination bands of about 15 Franck-Condon active vibrational modes based on the information provided in Table II. These 15 Franck-Condon active vibrational modes are the following: the nominal $\mathrm{CCH}$ bend $+\mathrm{CC}$ stretch $\nu_{12}\left(1326 \mathrm{~cm}^{-1}\right)$, the nominal CCC bend $\nu_{23}\left(564 \mathrm{~cm}^{-1}\right)$, the nominal $\mathrm{CO}$ stretch $+\mathrm{NO}$ stretch $+\mathrm{CC}$ stretch $\nu_{14}\left(1250 \mathrm{~cm}^{-1}\right)$, the nominal $\mathrm{CCH}$ bend $+\mathrm{CC}$ stretch $+\mathrm{COH}$ bend $\nu_{15}\left(1189 \mathrm{~cm}^{-1}\right)$; the nominal $\mathrm{CCH}$ bend $+\mathrm{CC}$ stretch $\nu_{17}\left(1134 \mathrm{~cm}^{-1}\right)$, the nominal CCC bend $+\mathrm{CC}$ stretch $\nu_{22}\left(669 \mathrm{~cm}^{-1}\right)$, the nominal $\mathrm{CCN}$ bend $\nu_{27}\left(291 \mathrm{~cm}^{-1}\right)$, the nominal $\mathrm{NO}_{2}$ bend $+\mathrm{CC}$ stretch $\nu_{21}\left(820 \mathrm{~cm}^{-1}\right)$, the nominal $\mathrm{CCO}$ bend $+\mathrm{CNO}$ bend $\nu_{25}\left(428 \mathrm{~cm}^{-1}\right)$, the nominal CC stretch $\nu_{7}\left(1590 \mathrm{~cm}^{-1}\right)$, the nominal NO stretch $\nu_{8}\left(1536 \mathrm{~cm}^{-1}\right)$, the nominal CCC bend $+\mathrm{NO}_{2}$ bend $\nu_{20}\left(870 \mathrm{~cm}^{-1}\right)$, the nominal CC stretch $\nu_{6}\left(1617 \mathrm{~cm}^{-1}\right)$, the nominal $\mathrm{COH}$ bend $+\mathrm{CC}$ stretch $\nu_{11}\left(1382 \mathrm{~cm}^{-1}\right)$, nominal $\mathrm{CCH}$ bend $+\mathrm{CC}$ stretch $\nu_{9}\left(1472 \mathrm{~cm}^{-1}\right)$. The vibrations of $\mathrm{OH}, \mathrm{NO}_{2}$, and the phenyl ring group were noted to be strongly mixed with each other and distributed among different modes. ${ }^{58}$ We note that the $\mathrm{CO}$ stretch is distributed among four active normal modes $\left(\nu_{12}, \nu_{14}, \nu_{21}, \nu_{9}\right)$, the $\mathrm{COH}$ in-plane bend is distributed among $\left(\nu_{11}, \nu_{13}, \nu_{15}\right)$, the CCO in-plane bend is distributed among $\left(\nu_{24}, \nu_{25}, \nu_{26}\right)$, the $\mathrm{NO}_{2}$ stretch is distributed among $\left(\nu_{13}, \nu_{14}\right)$, the CN stretch is distributed among $\left(\nu_{18}, \nu_{25}, \nu_{26}\right)$, the $\mathrm{NO}_{2}$ bend is distributed among $\left(\nu_{20}, \nu_{21}, \nu_{22}\right)$, the CNO bend is distributed among $\left(\nu_{22}, \nu_{23}, \nu_{24}, \nu_{25}, \nu_{27}\right)$, and the CC and CCC vibrations are distributed among almost all of Franck-Condon active modes. Photoexcitation of 2-nitrophenol in the CT-band absorption (also called the $A$-band absorption) appears to cause larger motions among the $\mathrm{CO}$ stretch, the $\mathrm{COH}$ bend, the $\mathrm{NO}_{2}$ bend, the $\mathrm{CNO}$ bend, and the phenyl ring deformation modes.

\section{Simulation of the absorption and resonance Raman spectra}

We have chosen to model the relative intensities of the 335 and $369 \mathrm{~nm}$ resonance Raman spectra since they are clearly mostly on resonance with the CT-band absorption. The 355 and $369 \mathrm{~nm}$ resonance Raman spectra have major progressions of the nominal $\mathrm{CCH}$ bend $+\mathrm{CC}$ stretch $\nu_{12}\left(1326 \mathrm{~cm}^{-1}\right)$ and its overtones as well as its combination bands with the nominal CCC bend $\nu_{23}\left(564 \mathrm{~cm}^{-1}\right)$, the nominal $\mathrm{CO}$ stretch $+\mathrm{NO}$ stretch $+\mathrm{CC}$ stretch $+\mathrm{CO}$ stretch $\nu_{14}\left(1250 \mathrm{~cm}^{-1}\right)$, the nominal $\mathrm{CCH}$ bend $+\mathrm{CC}$ stretch $+\mathrm{COH}$ bend $\nu_{15}\left(1189 \mathrm{~cm}^{-1}\right)$; the nominal CCH bend +CC stretch $\nu_{17}\left(1134 \mathrm{~cm}^{-1}\right)$, the nominal CCC bend $+\mathrm{CC}$ stretch $\nu_{22}\left(669 \mathrm{~cm}^{-1}\right)$, the nominal CCN bend $\nu_{27}\left(291 \mathrm{~cm}^{-1}\right)$, the nominal $\mathrm{NO}_{2}$ bend $+\mathrm{CC}$ stretch $\nu_{21}\left(820 \mathrm{~cm}^{-1}\right)$ as well as other normal modes. The absorption spectra and absolute resonance Raman cross sections were simulated using the time-dependent wave packet calculations and simple model described in Sec. II B. Table III presents the calculated parameters that best fit the absorption spectrum and the intensities of the 355 and $369 \mathrm{~nm}$ resonance Raman spectra for 
TABLE II. Experimental and B3LYP/631+G $(d f, p d)$ computed vibrational frequencies of 2-nitrophenol.

\begin{tabular}{|c|c|c|c|c|c|c|c|}
\hline \multirow[b]{2}{*}{ Symmetry } & \multirow[b]{2}{*}{ No. } & \multicolumn{2}{|c|}{ Calc. } & \multicolumn{3}{|c|}{ Expt. } & \multirow[b]{2}{*}{ Assignment } \\
\hline & & $\mathrm{a}$ & $\mathrm{b}$ & FT-R & FT IR & R. Raman & \\
\hline \multirow[t]{29}{*}{$A^{\prime}$} & $\nu_{1}$ & 345 & 334 & & & & $\mathrm{OH}$ stretch \\
\hline & $\nu_{2}$ & 322 & 312 & & & & $\mathrm{CH}$ stretch \\
\hline & $\nu_{3}$ & 320 & 310 & & & & $\mathrm{CH}$ stretch \\
\hline & $\nu_{4}$ & 319 & 309 & & $3237 w$ & & $\mathrm{CH}$ stretch \\
\hline & $\nu_{5}$ & 317 & 307 & $3086 w$ & $3114 w$ & & $\mathrm{CH}$ stretch \\
\hline & $\nu_{6}$ & 166 & 162 & $1617 w$ & $1614 \mathrm{~s}$ & 1617 & $\mathrm{CC}$ stretch \\
\hline & $\nu_{7}$ & 162 & 158 & $1590 \mathrm{~m}$ & $1589 \mathrm{~s}$ & 1590 & $\mathrm{CC}$ stretch \\
\hline & $\nu_{8}$ & 159 & 155 & $1536 \mathrm{~m}$ & $1531 \mathrm{~s}$ & 1536 & $\mathrm{NO}_{2}$ stretch $+\mathrm{CC}$ stretch \\
\hline & $\nu_{9}$ & 151 & 147 & $1476 v w$ & $1478 \mathrm{~s}$ & 1472 & $\mathrm{CCH}$ bend $+\mathrm{CC}$ stretch \\
\hline & $\nu_{10}$ & 149 & 145 & $1456 \mathrm{mw}$ & $1448 \mathrm{~m}$ & & $\mathrm{CCH}$ bend $+\mathrm{CC}$ stretch $+\mathrm{NO}$ stretch \\
\hline & $\nu_{11}$ & 142 & 138 & $1382 w$ & $1374 \mathrm{~m}$ & 1382 & $\mathrm{COH}$ bend $+\mathrm{CC}$ stretch \\
\hline & $\nu_{12}$ & 137 & 133 & $1326 \mathrm{~s}$ & $1311 w$ & 1326 & $\mathrm{CCH}$ bend $+\mathrm{CC}$ stretch $+\mathrm{CO}$ stretch \\
\hline & $\nu_{13}$ & 132 & 129 & & & & $\mathrm{NO}$ stretch $+\mathrm{CCH}$ bend \\
\hline & & 129 & 126 & & $1266 w$ & & $\mathrm{CO}$ stretch $+\mathrm{NO}_{2}$ stretch $+\mathrm{CC}$ \\
\hline & $\nu_{14}$ & 3 & 1 & $1250 \mathrm{~s}$ & & 1250 & stretch \\
\hline & & & & & $1251 w$ & & \\
\hline & $\nu_{15}$ & 123 & 120 & $1189 w$ & $1236 \mathrm{~m}$ & 1189 & $\mathrm{CCH}$ bend $+\mathrm{CC}$ stretch $+\mathrm{COH}$ bend \\
\hline & $\nu_{16}$ & 118 & 115 & & $1176 \mathrm{~s}$ & & $\mathrm{CCH}$ bend $+\mathrm{CC}$ stretch \\
\hline & $\nu_{17}$ & 115 & 113 & $1134 \mathrm{~s}$ & $1134 \mathrm{~m}$ & 1134 & $\mathrm{CCH}$ bend $+\mathrm{CC}$ stretch \\
\hline & $\nu_{18}$ & 110 & 107 & $1082 w$ & $1080 \mathrm{~m}$ & & $\mathrm{CCC}$ bend $+\mathrm{CC}$ stretch \\
\hline & $\nu_{19}$ & 104 & 102 & $1031 \mathrm{~s}$ & $1029 \mathrm{~m}$ & & $\mathrm{CC}$ stretch \\
\hline & $\nu_{20}$ & 885 & 867 & $870 \mathrm{~m}$ & $870 \mathrm{~m}$ & 870 & $\mathrm{CCC}$ bend $+\mathrm{NO}_{2}$ bend \\
\hline & $\nu_{21}$ & 839 & 823 & $820 \mathrm{~s}$ & $820 \mathrm{~m}$ & 820 & $\mathrm{NO}_{2}$ bend $+\mathrm{CC}$ stretch \\
\hline & $\nu_{22}$ & 683 & 672 & $669 w$ & & 669 & $\mathrm{CCC}$ bend $+\mathrm{CC}$ stretch \\
\hline & $\nu_{23}$ & 572 & 565 & $564 \mathrm{~m}$ & $564 w$ & & $\mathrm{CCC}$ bend $+\mathrm{CNO}$ bend \\
\hline & $\nu_{24}$ & 554 & 548 & $549 \mathrm{~m}$ & $548 \mathrm{~m}$ & & $\mathrm{CCC}$ bend $+\mathrm{CNO}$ bend \\
\hline & $\nu_{25}$ & 437 & 435 & $428 \mathrm{~m}$ & $422 \mathrm{~m}$ & 428 & $\mathrm{CCO}$ bend $+\mathrm{CNO}$ bend \\
\hline & $\nu_{26}$ & 382 & 382 & $372 w$ & & & $\mathrm{CCC}$ bend $+\mathrm{CN}$ stretch $+\mathrm{CCO}$ bend \\
\hline & $\nu_{27}$ & 291 & 295 & $285 \mathrm{~m}$ & & 291 & $\mathrm{CCC}$ bend $+\mathrm{CNO}$ bend \\
\hline \multirow[t]{12}{*}{$A^{\prime \prime}$} & $\nu_{28}$ & 999 & 977 & & & & $\mathrm{CH}$ wag \\
\hline & $\nu_{29}$ & 980 & 959 & & $957 w$ & & $\mathrm{CH}$ wag \\
\hline & $\nu_{30}$ & 871 & 854 & & $820 \mathrm{~m}$ & & $\mathrm{CH}$ wag \\
\hline & $\nu_{31}$ & 783 & 769 & $782 w$ & $785 \mathrm{~m}$ & & $\mathrm{CH}$ wag $+\mathrm{NO}_{2}$ wag \\
\hline & $\nu_{32}$ & 770 & 756 & $750 w$ & $747 \mathrm{~s}$ & & $\mathrm{NO}_{2}$ wag $+\mathrm{CH}$ wag \\
\hline & $\nu_{33}$ & 736 & 724 & & & & $\mathrm{CC}$ torsion $+\mathrm{CO}$ torsion $+\mathrm{NO}_{2}$ wag \\
\hline & $\nu_{34}$ & 694 & 683 & & $665 \mathrm{~s}$ & & $\mathrm{CO}$ torsion \\
\hline & $\nu_{35}$ & 537 & 532 & & $525 \mathrm{~s}$ & & $\mathrm{CC}$ torsion $+\mathrm{CO}$ torsion \\
\hline & $\nu_{36}$ & 428 & 427 & & & & $\mathrm{CC}$ torsion $+\mathrm{CN}$ torsion \\
\hline & $\nu_{37}$ & 249 & 254 & $254 \mathrm{mw}$ & & & $\mathrm{CC}$ torsion $+\mathrm{CO}$ torsion \\
\hline & $\nu_{38}$ & 146 & 155 & $161 \mathrm{~m}$ & & & $\mathrm{CC}$ torsion $+\mathrm{CO}$ torsion \\
\hline & $\nu_{39}$ & 80 & 91 & & & & $\mathrm{CN}$ torsion \\
\hline
\end{tabular}

B3LYP/6-31+G(df,pd)

${ }^{\mathrm{b}}$ Scaled $=13.9+0.964^{*}$ calculated

2-nitrophenol in cyclohexane solution. In order to simultaneously fit the absorption bandwidth and the pattern of the resonance Raman intensities, we needed to include a large amount of electronic dephasing (the $\Gamma$ parameter) and a large amount of inhomogeneous broadening (the $G$ parameter) in the calculations. This is similar to our previous work on gas and/or solution phase CT-band nitrobenzene and $B$-band nitroalkanes, ${ }^{18,19}$ where large damping parameters were needed to simultaneously fit the absolute Raman cross sections, the relative Raman intensity patterns, and the absorption band. This indicates that the population decay/electronic dephasing takes place substantially faster than just wave packet motion away from the Franck-Condon region. Table III shows that the electronic dephasing broadening of $670 \mathrm{~cm}^{-1}$ (the $\Gamma$ parameter) and inhomogeneous broadening of $890 \mathrm{~cm}^{-1}$ (the $G$ parameter) for 2-nitrophenol are considerably larger than the corresponding 580 and $500 \mathrm{~cm}^{-1}$ values found for nitrobenzene. The larger inhomogeneous broadening is most likely due to the additional inhomogeneous interaction of the ortho-OH group with the solvent cyclohexane, while the larger electronic dephasing is probably because of the more delocalized $\pi^{*}$ orbital (into the benzene ring and the $\mathrm{OH}$ group). These differences might indicate that intramolecular hydrogen bonding dissipates ad- 


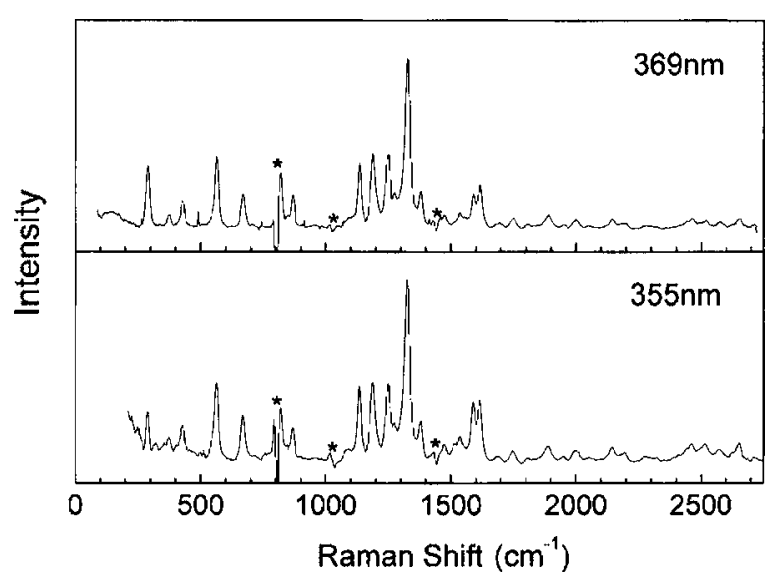

FIG. 3. Overall view of the A-band resonance Raman spectra of 2-nitrophenol in cyclohexane solvent obtained with the excitation wavelengths (in $\mathrm{nm}$ ) indicated next to each spectrum. The spectra have been intensity corrected and solvent subtracted (asterisks mark regions where solvent subtraction artifacts are present).

ditional excess energy through both homogeneous and inhomogeneous broadenings.

Since the CT-band resonance Raman spectra of 2-nitrophenol could possibly be susceptible to perturbation from preresonance-resonance interference effects ${ }^{16,35,48}$ from higher energy states, we have given greater weight to fitting the larger overtones and combination band features that are less likely to be influenced by the preresonance-resonance interference effects. The top panel of Fig. 5 shows a comparison of the calculated absorption spectrum with the experimental absorption spectrum while the bottom panel and Table IV show comparisons of the calculated resonance Raman cross sections (open bars) with the experimental Raman cross sections (solid bars) for the main Raman features of the 355 and $369 \mathrm{~nm}$ resonance Raman spectra. Inspection of Fig. 5 shows that there is reasonable agreement between the calculated and experimental absorption spectra and it is worth noting that the calculated spectrum is consistent with the oscillator strength of the CT transition while simultaneously providing a good fit to the absolute Raman intensities of the 355 and $369 \mathrm{~nm}$ spectra, as shown in the lower part of Fig. 5.

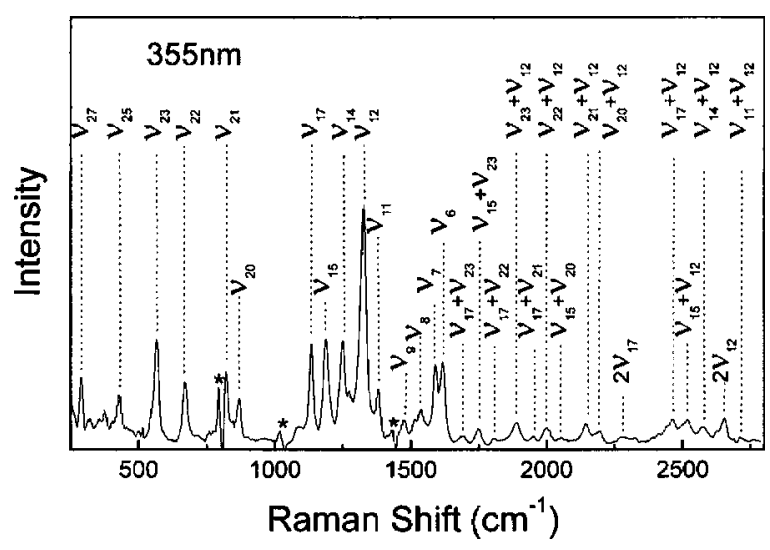

FIG. 4. Expanded view of the $355 \mathrm{~nm}$ resonance Raman spectrum of 2-nitrophenol in cyclohexane solvent. The spectrum has been intensity corrected and solvent subtracted. Asterisks label parts of the spectrum where solvent subtraction artifacts are present. The tentative assignments to the larger Raman band features are also shown.
If any of the parameters in Table III are changed beyond their estimated uncertainties (about $\pm 5 \%-10 \%$ ), the calculated fit to the absorption spectrum and/or resonance Raman cross section becomes noticeably poorer. The overall best fit to both the absorption spectrum and the absolute resonance Raman intensities appears reasonable to extract the major features of the transition and its associated short-time dynamics on the excited state potential energy surface.

Examination of the $|\Delta|$ dimensionless parameters in Table III obtained by fitting the absorption spectrum and the resonance Raman cross sections shows that the largest changes in the displacements take place with the nominal $\mathrm{CCH}$ bend+CC stretch mode $\nu_{12}(|\Delta|=0.85)$ and the $\nu_{23}(|\Delta|=1.03)$ mode. There are also more modest contributions from the nominal $\mathrm{CO}$ stretch $+\mathrm{NO}$ stretch $+\mathrm{CC}$ stretch $\nu_{14}(|\Delta|=0.58)$, the nominal $\mathrm{CCH}$ bend $+\mathrm{CC}$ stretch $+\mathrm{COH}$ bend $\nu_{15}(|\Delta|=0.55)$; the nominal CCH bend $+\mathrm{CC}$ stretch $\nu_{17}$ $(|\Delta|=0.52)$, the nominal CCC bend+CC stretch $\nu_{22}(|\Delta|$ $=0.68)$, the nominal CCN bend $\nu_{27}(|\Delta|=1.06)$, the nominal $\mathrm{NO}_{2}$ bend $+\mathrm{CC}$ stretch $\nu_{21}(|\Delta|=0.54)$, and other seven normal modes. Our results indicate that the short-time photodissociation dynamics of 2-nitrophenol have significant multidimensional character distributed over a wide variety of vibrational modes.

\section{E. The A-band 2-nitrophenol photodissociation dynamics and comparison to previous work on nitrobenzene, p-nitroaniline, and 2-hydroxyacetophenone}

Nitrobenzene and $p$-nitroaniline are two prototypical charge-transfer molecules for which resonance Raman intensity analysis has been done. ${ }^{25,56}$ The resonance Raman spectra and intensity analysis indicate that most of the short-time photodissociation dynamics of nitrobenzene in the FranckCondon region occurs along the nominal $\mathrm{NO}_{2}$ stretch and nominal benzene ring symmetry stretch normal modes, accompanied by smaller components along the nominal ONO symmetry bend/benzene ring stretch mode, the nominal C-N stretch/benzene ring breathing mode, the nominal CCC bending mode, and the nominal $\mathrm{CCH}$ in-plane bending mode. Comparison of the normal mode displacements and the vibrational reorganizational energies found from the 355 and $369 \mathrm{~nm}$ CT-band resonance Raman spectra of 2-nitrophenol to those previously found for nitroalkanes and nitrobenzene reveals some interesting differences. Firstly, while the short-time dynamics for nitrobenzene were found to be noticeably different from those of nitroalkanes with substantially less vibrational reorganizational energy $\left(3369 \mathrm{~cm}^{-1}\right)$ taking place in the Franck-Condon region of nitrobenzene compared to the nitroalkanes $\left(4700 \mathrm{~cm}^{-1}\right.$ for the nitromethane or $6180 \mathrm{~cm}^{-1}$ for the nitroethane and $6255 \mathrm{~cm}^{-1}$ for the nitropropane), the total vibrational reorganizational energy $2433 \mathrm{~cm}^{-1}$ for 2-nitrophenol is considerably less than the corresponding $3369 \mathrm{~cm}^{-1}$ for nitrobenzene. We note that among the $4700 \mathrm{~cm}^{-1}$ total vibrational organizational energy determined from the $B$-band resonance Raman intensity analysis of nitromethane (or the $6180 \mathrm{~cm}^{-1}$ for the nitroethane and the $6255 \mathrm{~cm}^{-1}$ for the nitropropane), almost all of the energy is allocated to the $\mathrm{NO}_{2}$ symmetry 
TABLE III. Parameters for time-dependent wave packet calculations and the resulting vibrational reorganization energy for 2-nitrophenol and nitrobenzene (for comparison). The abbreviations $\mathrm{s}$ and $\mathrm{b}$ mean stretch and in-plane bend, respectively.

\begin{tabular}{|c|c|c|c|}
\hline Vibrational mode and $\mathrm{PED}^{\mathrm{a}}$ & Freq & $|\Delta|$ & Vibrational reorganization \\
\hline \multicolumn{4}{|c|}{ 2-nitrophenol ${ }^{\mathrm{b}}$} \\
\hline$\nu_{27} / \mathrm{CCN}$ b $(71), \mathrm{CNO}$ b (17) & 290 & 1.06 & 163 \\
\hline$\nu_{25} / \mathrm{CCO} \mathrm{b}(31), \mathrm{CNO}$ b (31), CCC b (13), CN s (10) & 428 & 0.74 & 117 \\
\hline$\nu_{23} / \mathrm{CCC}$ b (37), CNO b (18), CC s (18), CCN b (11) & 564 & 1.03 & 299 \\
\hline$\nu_{22} / \mathrm{CCC} \mathrm{b}(47), \mathrm{CC}$ s $(21), \mathrm{NO}_{2} \mathrm{~b}(13), \mathrm{CNO} \mathrm{b}(10)$ & 669 & 0.68 & 155 \\
\hline$\nu_{21} / \mathrm{NO}_{2} \mathrm{~b}(35), \mathrm{CC} \mathrm{s}(31), \mathrm{CCC} \mathrm{b}(12), \mathrm{CO} \mathrm{s}(11)$ & 820 & 0.54 & 120 \\
\hline$\nu_{20} / \mathrm{CCC} \mathrm{b}(45), \mathrm{NO}_{2} \mathrm{~b}(23), \mathrm{NO} \mathrm{s}(12)$ & 870 & 0.44 & 84 \\
\hline$\nu_{17} / \mathrm{CCH} \mathrm{b}(43), \mathrm{CC} \mathrm{s}(37)$ & 1134 & 0.52 & 153 \\
\hline$\nu_{15} / \mathrm{CCH}$ b (37), CC s (29), COH b (22) & 1190 & 0.55 & 180 \\
\hline$\nu_{14} / \mathrm{CO} \mathrm{s}(26), \mathrm{NO} \mathrm{s}(24), \mathrm{CC} \mathrm{s}(22)$ & 1250 & 0.58 & 210 \\
\hline$\nu_{12} / \mathrm{CCH} \mathrm{b}(28), \mathrm{CC} \mathrm{s}(25), \mathrm{CO} \mathrm{s}(18)$ & 1326 & 0.85 & 479 \\
\hline$\nu_{11} / \mathrm{COH} \mathrm{b}(32), \mathrm{CC} \mathrm{s}(26), \mathrm{CCH} \mathrm{b}(19), \mathrm{NO} \mathrm{s}(16)$ & 1382 & 0.28 & 54 \\
\hline$\nu_{9} / \mathrm{CCH} \mathrm{b}(51), \mathrm{CC} \mathrm{s}(31), \mathrm{CO} \mathrm{s}(11)$ & 1472 & 0.23 & 39 \\
\hline$\nu_{8} / \mathrm{NO} \mathrm{s}(53), \mathrm{CC} \mathrm{s}(19), \mathrm{CCH} \mathrm{b}(11)$ & 1538 & 0.32 & 79 \\
\hline$\nu_{7} / \mathrm{CC} \mathrm{s}(63), \mathrm{CCH} \mathrm{b}(11), \mathrm{CCC}$ b (10) & 1590 & 0.32 & 81 \\
\hline$\nu_{6} / \mathrm{CC} \mathrm{s}(53), \mathrm{NO} \mathrm{s}(12), \mathrm{CCH} \mathrm{b}(12)$ & 1617 & 0.35 & 99 \\
\hline
\end{tabular}

Total $=2312$

Transition length $M=0.653, E_{00}=26810 \mathrm{~cm}^{-1}, \Gamma=670 \mathrm{~cm}^{-1}, G$ (standard deviation) $=890 \mathrm{~cm}^{-1}$

\begin{tabular}{cclr}
\multicolumn{4}{c}{ Nitrobenzene $^{\mathrm{a}}$} \\
$\nu_{23} / \mathrm{ONO}$ symmetry bend+ring stretch & 849 & 0.9 & 344 \\
$\nu_{20} / \mathrm{CCC}$ trigonal bend & 1002 & 0.64 & 205 \\
$\nu_{16} / \mathrm{C}-\mathrm{N}$ stretch+ring breath & 1117 & 0.66 & 243 \\
$\nu_{14} / \mathrm{CCH}$ in-plane bend & 1174 & 0.22 & 28 \\
$\nu_{11} / \mathrm{NO}_{2}$ symmetry stretch & 1350 & 1.68 & 1905 \\
$\nu_{7} /$ ring stretch & 1589 & 0.9 & 644 \\
& & & Total $=3369$
\end{tabular}

Transition length $M=0.955, E_{00}=36800 \mathrm{~cm}^{-1}, \Gamma=580 \mathrm{~cm}^{-1}, G($ standard deviation $)=500 \mathrm{~cm}^{-1}$

${ }^{\mathrm{a}}$ From Ref. 58.
${ }^{\mathrm{b}}$ From Ref. 25.

stretch mode. In contrast, the $3369 \mathrm{~cm}^{-1}$ vibrational reorganizational energy of nitrobenzene is distributed over six normal modes and the $2433 \mathrm{~cm}^{-1}$ vibrational reorganizational energy of 2-nitrophenol is partitioned into 15 normal modes. This indicates that 2-nitrophenol not only appears to have a more complex reaction coordinate in the Franck-Condon region dynamics but also has less energy going into vibrational degrees of freedom with respect to nitrobenzene and nitroalkanes. The lack of significant substituent effects on the $B$-band Franck-Condon region photodissociation dynamics and the corresponding resonance Raman spectra of nitroalkanes is most likely due to a clear separation of the time scale for the motion on the initial excited state potential energy surface compared with the vibrational motion in the rest of the molecule. This would help explain why the intensity pattern of the predominant $\mathrm{NO}_{2}$ symmetric stretch overtone progression tends to be preserved even as the nitroalkanes become heavier and more branched. In contrast, the CT-band resonance Raman spectra of nitrobenzene display significantly different Raman intensity patterns from those of the nitroalkanes previously studied. The multidimensionality of the Franck-Condon region CT-band photodissociation dynamics of nitrobenzene and 2-nitrophenol and their obvious substituent effects suggest that the time scale for the wave packet motion on the initial excited state potential energy surface is comparable to the vibrational motion in the rest of the molecule. This is most likely due to the delocalized $\pi$ (benzene ring) $\rightarrow \pi^{*}\left(\mathrm{NO}_{2}\right)$ transition, which is characteristically an intramolecular charge-transfer excitation or a very strong excited state electronic coupling between the nitro and benzene groups in nitrobenzene or a very strong excited state electronic/proton coupling between the nitro group, the benzene group, and the hydroxy group in 2-nitrophenol. The distinct difference in the nature of the electronic transitions in 2-nitrophenol, nitrobenzene, and nitroalkanes leads to noticeable differences in the short-time dynamics of these types of nitro compounds.

Further examination of the intensity patterns of the resonance Raman spectra and the corresponding normal mode displacements in 2-nitrophenol and nitrobenzene reveal distinct differences in their Franck-Condon dynamics. The short-time photodissociation dynamics of nitrobenzene are predominantly along $\mathrm{NO}_{2}$ and benzene ring reaction coordinates (with the $\mathrm{NO}_{2}$ stretch and the benzene ring stretch modes taking up about $56 \%$ and $20 \%$ of the total vibrational reorganizational energy, respectively). In contrast the 

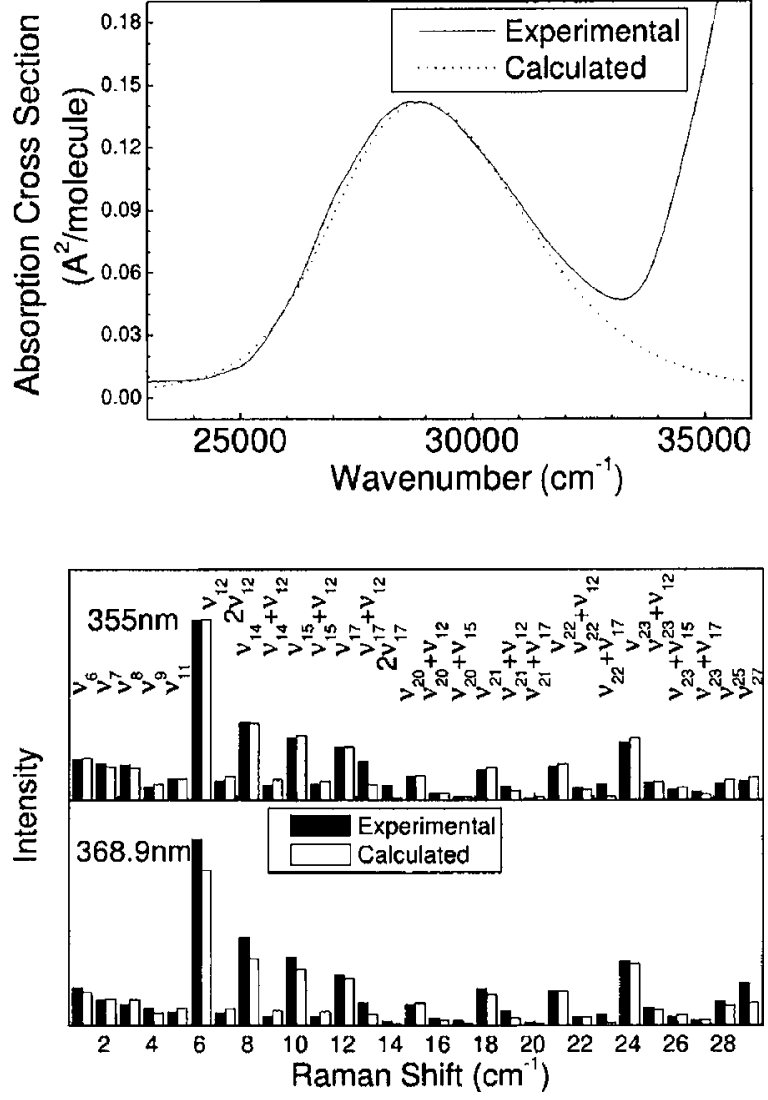

FIG. 5. (Top) Comparison of the computed absorption spectrum (dotted line) with the experimental (solid line) absorption spectrum. (Bottom) Comparison of the computed resonance Raman cross sections (open bars) with the experimental Raman cross sections (solid bars) for the main Raman features of the $266 \mathrm{~nm}$ and $252.7 \mathrm{~nm}$ resonance Raman spectra. The computations made use of the model described in Ref. 25 with the simple exponential decay dephasing treatment for the solvent (see text for details).

Franck-Condon region dynamics of 2-nitrophenol along the $\mathrm{NO}_{2}$ stretch coordinate is greatly hindered, indicating that the intramolecular hydrogen bonding greatly reduced the Franck-Condon dynamics along the $\mathrm{NO}_{2}$ motion of 2-nitrophenol. Instead the $\mathrm{COH}$ bend, the $\mathrm{CO}$ stretch, the $\mathrm{NO}_{2}$ bend, the $\mathrm{CNO}$ bend, and the phenyl ring stretch/ bending modes become the main reaction coordinates. Obviously the substitution of the ortho- $\mathrm{H}$ atom of the benzene ring by the hydroxy group have greatly altered the FranckCondon region photodissociation dynamics of nitrobenzene with the $\mathrm{COH}$ bend, the $\mathrm{CO}$ stretch, the $\mathrm{NO}_{2}$ bend, and the $\mathrm{CNO}$ bend modes being substantially activated while the $\mathrm{NO}_{2}$ stretch modes become hindered. This is consistent with the features for the geometry changes of the ground state proton transfer reaction.

$p$-nitroaniline (PNA) has a stronger charge-transfer character relative to nitrobenzene. ${ }^{59}$ While the absorption spectrum of PNA in cyclohexane solution is shifted by about $9000 \mathrm{~cm}^{-1}$ to the red of nitrobenzene, the resonance Raman intensity patterns of PNA are basically quite similar to those of nitrobenzene. Especially the three largest $\Delta$ modes, the symmetric $\mathrm{NO}_{2}$ stretch at $1338 \mathrm{~cm}^{-1}(\Delta=1.43)$, the benzene ring stretch at $1599 \mathrm{~cm}^{-1}(\Delta=0.496)$, and the $\mathrm{NO}_{2}$ scissors at $859 \mathrm{~cm}^{-1}(\Delta=0.88)$ for PNA in cyclohexane are quite close to the symmetric $\mathrm{NO}_{2}$ stretch at $1350 \mathrm{~cm}^{-1}(\Delta=1.65)$, the benzene ring stretch at $1589 \mathrm{~cm}^{-1}(\Delta=0.9)$, and the $\mathrm{NO}_{2}$ scissors at $849 \mathrm{~cm}^{-1}(\Delta=0.9)$ for nitrobenzene in cyclohexane. This might indicate that while the substitution of the $p-\mathrm{H}$ atom of the benzene ring by an amino group considerably lowers the electronic transition energy for the phenyl highest occupied molecular orbital to the nitro lowest unoccupied molecular orbital it does not significantly alter the nature of the initial Franck-Condon region photodissociation dynamics. Solvents do not appear to substantially alter the nature of the initial Franck-Condon region photodissociation dynamics of $p$-aniline too much since the short-time photodissociation dynamics of $\mathrm{p}$-aniline in methanol solution are quite similar to that in cyclohexane solution. ${ }^{59}$ Therefore, the similar Franck-Condon region dynamics between PNA and nitrobenzene might indicate that the intermolecular hydrogen bonding does not dramatically alter the Franck-Condon region photodissociation dynamics for nitroaromatic molecules in their CT-band absorptions.

OHAP is a prototypical proton transfer molecule for which resonance Raman intensity analysis was carried out for its proton transfer coupled electronic absorption band. ${ }^{56}$ Fourteen vibrational modes were found to be significantly enhanced with the most intense Raman band being the symmetric stretch of the benzene ring $1324 \mathrm{~cm}^{-1}$. An absolute Raman intensity analysis indicated that the breadth of the absorption and emission bands in OHAP was due to displacements in 14 vibrational coordinates not including the $\mathrm{O}-\mathrm{H}$ stretch and the electronically excited OHAP evolves rapidly in the Franck-Condon region along a large number of skeletal coordinates without involving the hydroxy stretching coordinate. The Franck-Condon region proton transfer dynamics of 2-nitrophenol is similar to that of OHAP. We have noted that OHAP has $2805 \mathrm{~cm}^{-1}$ total vibrational reorganizational energy that is distributed into 14 vibrational modes with $>65 \%$ of the total vibrational reorganizational energy being partitioned into the seven largest normal modes (the nominal benzene skeletal, the nominal $\mathrm{COH}$ group, and the nominal carbonyl group stretch/bending modes). The benzene skeletal motions possess the largest amount of vibrational reorganizational energy. This is qualitatively similar to 2-nitrophenol that has about $2433 \mathrm{~cm}^{-1}$ total vibrational reorganizational energy that is partitioned among is FranckCondon vibrational modes, with about $65 \%$ of the total vibrational reorganizational energy being partitioned into the six largest normal modes (the nominal benzene skeletal and the nominal $\mathrm{COH}$ group stretch/bending modes). The benzene skeletal modes also have the largest reorganizational energy. The hydroxy stretching mode is not observed in the 355 and $369 \mathrm{~nm}$ resonance Raman spectra of 2-nitrophenol and this is similar to the resonance Raman results for OHAP. OHAP was believed to undergo a barrierless proton transfer reaction in its first excited state. ${ }^{60,61}$ The absence of intensity in the hydroxy stretching mode as well as its combination bands with the nominal benzene skeletal modes in the resonance Raman spectrum for both 2-nitrophenol and OHAP suggest a mechanistic picture of the excited state proton transfer reaction in which an overall molecular geometry change comprised multiple reaction coordinates rather than along a separable single hydroxy stretch reaction coordinate. 
TABLE IV. Resonance Raman intensities of $o$-nitrophenol in cyclohexane solution.

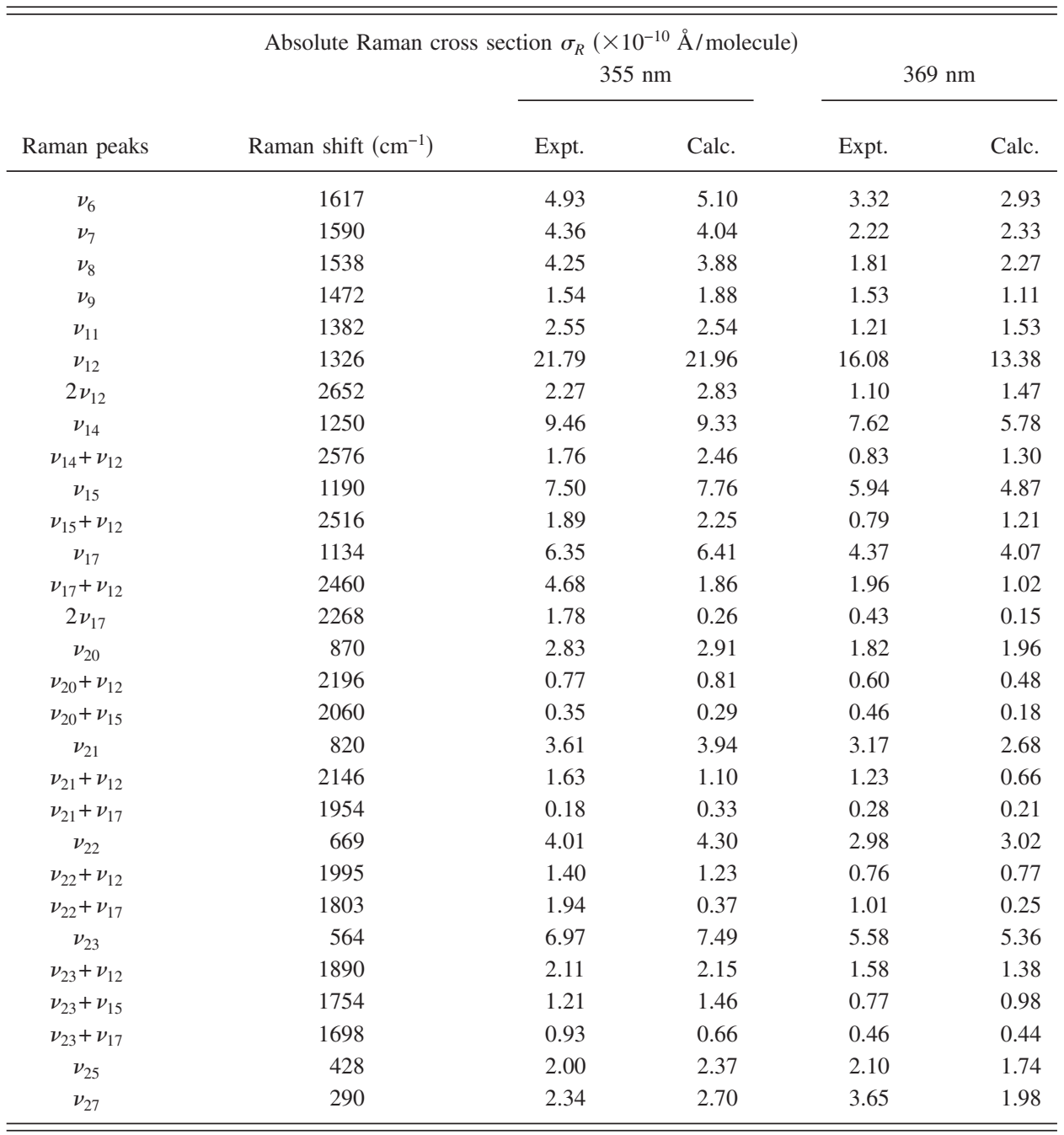

It is likely that skeletal motion occurs prior to or concertedly with the excited state proton transfer taking place in these systems.

We have noted that the ground state proton transfer isomer for OHAP differs from that of 2-nitrophenol in that the former has a facial isomer whereas the latter has a backward isomer. This difference causes 2-nitrophenol to have distorted transition state structures (with the $-\mathrm{ON}-\mathrm{OH}$ moiety being bent away from the molecular symmetry plane) whereas OHAP still has a planiform one. Since we do not observe any noticeable out-of-plane vibrational modes for the CT-band resonance Raman spectra of 2-nitrophenol, it is suggested that the transition state for IESPT of 2-nitrophenol would be far away from Franck-Condon region if it exists. Otherwise the IESPT for 2-nitrophenol would be a barrierless process.

The photodissociation reaction mechanism for nitrobenzene was proposed to be that the nitrobenzene molecule first isomerized to phenyl nitrite $\mathrm{C}_{6} \mathrm{H}_{5} \mathrm{ONO}$ and subsequently decomposed by breaking the C-ONO bond to release $\mathrm{NO}_{2}$, or the $\mathrm{O}-\mathrm{NO}$ bond to produce $\mathrm{NO}$, or the $\mathrm{ON}-\mathrm{O}$ bond to form O. ${ }^{22-24}$ The Franck-Condon region photodissociation dynamics of nitrobenzene in cyclohexane solution were studied by using resonance Raman spectroscopy and DFT computations. ${ }^{25}$ The resonance Raman spectra and intensity analysis indicate that the major short-time photodissociation dynamics in the Franck-Condon region occurs mostly along the nominal $\mathrm{NO}_{2}$ stretch and nominal benzene ring symmetry stretch normal modes accompanied by other four smaller normal modes and that the most important reaction coordinate for nitrobenzene is along the $\mathrm{NO}_{2}$ stretch mode. There are not many investigations for the photodissociation reaction mechanism of 2-nitrophenol and its dynamics are still not clear. The photochemistry of 2-nitrophenol was studied by Alif et al. and 2-nitrosophenol, catechol, 3-nitrocatachol as well as nitrous acid were determined to be the main photoproducts for 2-nitrophenol photolysis in acidic solution. ${ }^{62}$ 2-nitrosophenol and 3-nitrocatechol photoproducts were thought to support that the $\mathrm{OH}$ radical and the $\mathrm{N}-\mathrm{OH}$ bond fission of the IESPT intermediate occurred during the IESPT processes of 2-nitrophenol. The quantum yield of the direct phototransformation of 2-nitrophenol is very low $\left(\phi_{365} \mathrm{~nm}\right.$ $=4.7 \times 10^{-6}$ at $p \mathrm{H} 2.2$ ) and is dependent on the photolysis wavelength $\left(\phi_{253.7 \mathrm{~nm}}=7.8 \times 10^{-4}\right.$ at $\left.p \mathrm{H} 2.2\right)$. Our resonance Raman results show that the Franck-Condon region proton transfer dynamics are mostly along the $\mathrm{CO}$ stretch, the $\mathrm{COH}$ bend, the $\mathrm{NO}_{2}$ bend, and the $\mathrm{CNO}$ bend reaction coordinates rather than along the $\mathrm{NO}_{2}$ stretch coordinate. This suggests 
that the ground state intramolecular hydrogen bonding tunes the Franck-Condon region photodissociation dynamics from a nitro-nitrite phototransformation of nitrobenzene to the IESPT photoisomerization of 2-nitrophenol. The very different kinds of photoproducts observed for nitrobenzene and 2-nitropheno are most likely due to the very different Franck-Condon photodissociation dynamics.

\section{CONCLUSION}

CT-band resonance Raman spectra were acquired for 2-nitrophenol in cyclohexane solution. The resonance Raman spectra and intensity analysis of these spectra indicate that most of the short-time photodissociation dynamics in the Franck-Condon region occurs mostly along the nominal $\mathrm{CCH}$ bend $+\mathrm{CC}$ stretch mode $\nu_{12}(|\Delta|=0.85, \lambda=479)$ and the $\nu_{23} \quad(|\Delta|=1.03, \quad \lambda=299)$, the nominal $\mathrm{CO}$ stretch+NO stretch $+\mathrm{CC}$ stretch $\nu_{14}(|\Delta|=0.58, \lambda=210)$, the nominal $\mathrm{CCH}$ bend $+\mathrm{CC}$ stretch $+\mathrm{COH}$ bend $\nu_{15}(|\Delta|=0.55, \lambda=180)$; the nominal $\mathrm{CCH}$ bend $+\mathrm{CC}$ stretch $\nu_{17}(|\Delta|=0.52, \lambda=153)$, the nominal CCC bend $+\mathrm{CC}$ stretch $\nu_{22}(|\Delta|=0.68, \lambda=155)$, the nominal $\mathrm{CCN}$ bend $\nu_{27}(|\Delta|=1.06, \lambda=163)$, the nominal $\mathrm{NO}_{2}$ bend $+\mathrm{CC}$ stretch $\nu_{21}(|\Delta|=0.54, \lambda=120)$. There are also smaller components along other seven normal modes. These results for 2-nitrophenol were compared to those previously reported for nitrobenzene, $p$-nitroaniline (PNA), and 2-hydroxyacetophenone (OHAP). The short-time dynamics for 2-nitrophenol were found to be similar to those for OHAP and this indicates that most of available vibrational energy is being partitioned to the skeletal vibrational motions for 2-nitrophenol. This energy partitioning is very different from those previously determined for nitrobenzene and PNA where most of the available vibrational energy takes place in the symmetry $\mathrm{NO}_{2}$ stretch/bending vibrations for nitrobenzene and PNA. We briefly discussed possible implications for this behavior for the photochemistry of 2-nitrophenol.

\section{ACKNOWLEDGMENTS}

This work was supported by grants from NSFC (No. 20573097 and No. 20273062), Zhejiang NSF (No. R405465), EYTP, MOE of China (No. 1918), of China to one of the author (X.Z.), and from the Research Grants Council (RGC) of Hong Kong (HKU 7021/03P) to another author (D.L.P.).

${ }^{1}$ B. N. Kondridov, G. D. Kozad, V. M. Raikova, and A. V. Starshinov, Sov. Phys. Dokl. 233, 402 (1977).

${ }^{2}$ W. Tsang, D. Robaugh, and W. J. Mallard, J. Phys. Chem. 90, 5968 (1986).

${ }^{3}$ H. S. Kwok, G. Z. He, R. K. Sparks, and Y. T. Lee, Int. J. Chem. Kinet. 13, 1125 (1981)

${ }^{4}$ A. A. Turnipseed, G. L. Vaghjiani, J. E. Thompson, and A. R. Ravishankara, J. Chem. Phys. 96, 5887 (1992).

${ }^{5}$ S. Nagakura, Mol. Phys. 3, 152 (1960).

${ }^{6}$ L. E. Harris, J. Chem. Phys. 58, 5615 (1973).

${ }^{7}$ W. M. Flicker, O. A. Mosher, and A. Kuppermann, Chem. Phys. Lett. 60 , 518 (1979).

${ }^{8}$ W. M. Flicker, O. A. Mosher, and A. Kuppermann, J. Chem. Phys. 72, 2788 (1980).

${ }^{9}$ D. A. Kleier and M. A. Lipton, J. Mol. Struct.: THEOCHEM 109, 39 (1984)

${ }^{10}$ C. Mijoule, S. Odiot, S. Fliszar, and J. M. Schnur, J. Mol. Struct.: THEOCHEM 149, 311 (1987).
${ }^{11}$ L. J. Butler, D. Drajnovich, Y. T. Lee, G. Ondrey, and R. Bersohn, J. Chem. Phys. 79, 1708 (1983).

${ }^{12}$ N. C. Blais, J. Chem. Phys. 79, 1723 (1983).

${ }^{13}$ K. Q. Lao, E. Jensen, P. W. Kash, and L. J. Butler, J. Chem. Phys. 93, 3958 (1990)

${ }^{14}$ D. B. Moss, K. A. Trentelman, and P. L. Houston, J. Chem. Phys. 96, 237 (1992).

${ }^{15}$ A. M. Wodtke, E. J. Hintsa, and Y. T. Lee, J. Phys. Chem. 90, 3549 (1986).

${ }^{16}$ D. L. Phillips and A. B. Myers, J. Phys. Chem. 95, 7164 (1991).

${ }^{17}$ C. W. Lee, X. Zheng, and D. L. Phillips, Asian J. Spectrosc. 3, 69 (1999).

${ }^{18}$ W. M. Kwok, M. S. Hung, and D. L. Phillips, Mol. Phys. 88, 517 (1996).

${ }^{19}$ M. S. Hung, W. M. Kwok, and D. L. Phillips, Mol. Phys. 93, 173 (1998).

${ }^{20}$ M. R. Robin, Higher Excited States of Polyatomic Molecules (Academic, New York, 1975), Vol. II, p. 251.

${ }^{21}$ O. Kröhl, K. Malsch, and P. Swiderek, Phys. Chem. Chem. Phys. 2, 947 (2000).

${ }^{22}$ D. B. Galloway, A. Bartz, L. G. Huey, and F. F. Crim, J. Chem. Phys. 98, 2107 (1993)

${ }^{23}$ T. Clenewinkel-Meyer and F. F. Crim, J. Mol. Struct.: THEOCHEM 337, 209 (1995).

${ }^{24}$ Y. M. Li, J. L. Sun, H. M. Yin, K. L. Han, and G. Z. He, J. Chem. Phys. 118, 6244 (2003).

${ }^{25}$ X. Zhu, S. Zhang, X. Zheng, and D. L. Phillips, J. Phys. Chem. A 109, 3086 (2005).

${ }^{26}$ K. J. Castle, J. Abbott, X. Z. Peng, and W. Kong, J. Chem. Phys. 113, 1415 (2000).

${ }^{27}$ C. Kosmidis, W. D. Ledingham, H. S. Kilic, T. McCanny, R. P. Singhal, A. J. Langley, and W. Shaikh, J. Phys. Chem. A 101, 2264 (1997).

${ }^{28}$ J. Shao and T. Baer, Int. J. Mass Spectrom. Ion Process. 86, 357 (1988).

${ }^{29}$ A. Marshall, A. Clark, K. W. D. Ledingham, J. Sander, and R. P. Singhal, Int. J. Mass Spectrom. Ion Process. 125, 21 (1993).

${ }^{30}$ S. A. Asher, Annu. Rev. Phys. Chem. 39, 537 (1988).

${ }^{31}$ W. M. Kwok and D. L. Phillips, Chem. Phys. Lett. 235, 260 (1995).

${ }^{32}$ D. L. Phillips and W. M. Kwok, Chem. Phys. Lett. 241, 267 (1995).

${ }^{33}$ S. Q. Man, W. M. Kwok, and D. L. Phillips, J. Phys. Chem. 99, 15705 (1995).

${ }^{34}$ W. M. Kwok and D. L. Phillips, J. Chem. Phys. 104, 2529 (1996).

${ }^{35}$ W. M. Kwok and D. L. Phillips, J. Chem. Phys. 104, 9816 (1996).

${ }^{36}$ S. Q. Man, W. M. Kwok, A. E. Johnson, and D. L. Phillips, J. Chem. Phys. 105, 5842 (1996).

${ }^{37}$ W. M. Kwok, P. K. Ng, G. Z. He, and D. L. Phillips, Mol. Phys. 90, 127 (1997).

${ }^{38}$ D. L. Phillips and A. B. Myers, J. Raman Spectrosc. 28, 839 (1997).

${ }^{39}$ X. Zheng and D. L. Phillips, Chem. Phys. Lett. 286, 79 (1998).

${ }^{40}$ X. Zheng and D. L. Phillips, Chem. Phys. Lett. 292, 295 (1998).

${ }^{41}$ X. Zheng and D. L. Phillips, J. Chem. Phys. 108, 5772 (1998).

${ }^{42}$ X. Zheng and D. L. Phillips, Chem. Phys. Lett. 307, 350 (1999).

${ }^{43}$ X. Zheng and D. L. Phillips, Chem. Phys. Lett. 296, 173 (1998).

${ }^{44}$ X. Zheng, C. W. Lee, and D. L. Phillips, J. Chem. Phys. 111, 11034 (1999).

${ }^{45}$ S. Y. Lee and E. J. Heller, J. Chem. Phys. 71, 4777 (1979).

${ }^{46}$ E. J. Heller, R. L. Sundberg, and D. J. Tannor, J. Phys. Chem. 86, 1822 (1982).

${ }^{47}$ A. B. Myers and R. A. Mathies, in Biological Applications of Raman Spectroscopy, edited by T. G. Spiro (Wiley, New York, 1987), Vol. 2, p. 1.

${ }^{48}$ A. B. Myers, in Laser Techniques in Chemistry, edited by A. B. Myers and T. R. Rizzo (Wiley, New York, 1995), p. 325.

${ }^{49}$ A. Becke, J. Chem. Phys. 84, 4524 (1986).

${ }^{50}$ C. Lee, W. Yang, and R. G. Parr, Phys. Rev. B 37, 785 (1988).

${ }^{51}$ M. J. Frisch, G. W. Trucks, H. B. Schlegel et al., GaUssian 98, Revision A.1, Revision A.7, Gaussian, Inc., Pittsburgh, PA, 1998.

${ }^{52}$ (a) P. C. Chen and Y. C. Chieh, Chem. Phys. Lett. 372, 147 (2003); (b) T. B. Brill and K. J. James, NTIS Report No. AD-A279600, 1994 (unpublished).

${ }^{53}$ P. Politzer, J. M. Seminario, and P. R. Bolduc, Chem. Phys. Lett. 158, 463 (1989).

${ }^{54}$ P. C. Chen, W. Lo, and S. C. Tzeng, J. Mol. Struct.: THEOCHEM 428, 257 (1998).

${ }^{55}$ P. C. Chen and Y. C. Chieh, Chem. Phys. Lett. 372, 147 (2003).

${ }^{56}$ L. A. Peteanu and R. A. Mathies, J. Chem. Phys. 96, 6910 (1992).

${ }^{57}$ T. Ari, H. Güven, and N. Ecevit, J. Electron Spectrosc. Relat. Phenom. 73, 13 (1995). 
${ }^{58}$ A. Kovacs, V. Izvekov, G. Keresztury, and G. Pongor, Chem. Phys. 238, 231 (1998).

${ }^{59}$ A. M. Moran and A. M. Kelley, J. Chem. Phys. 115, 912 (2001).

${ }^{60}$ P. F. Barbara, P. K. Walsh, and L. E. Brus, J. Phys. Chem. 93, 29 (1989).
${ }^{61}$ T. Nishiya, S. Yamauchi, N. Hirota, M. Baba, and I. Hanazaki, J. Phys. Chem. 90, 5730 (1986).

${ }^{62}$ A. Alif, J. F. Pilichowski, and P. Boule, J. Photochem. Photobiol., A 59, 209 (1991). 